4. Por vezes os processos químicos tecnológicos têm efeitos secundários nocivos. Mas cabe à própria Química (e Engenharias Química e do Ambiente, etc.) resolver os problemas, que resultam de um conhecimento ou de precauções insuficientes. A indústria química é hoje muito menos poluente do que no passado, sendo também uma das mais seguras. Os fumos que continuamos a ver em imagens que supostamente documentam poluição, são quase sempre apenas água líquida finamente dividida (suspensões de gotículas resultantes da condensação local de vapor de água, sendo este invisível nessas emissões).

5. Mas o contributo da Química não se esgota nas novas moléculas e nos novos materiais. O desenvolvimento de novas reacções e processos mais eficazes (em rendimento, energia, etc.) e me- nos poluentes, ainda que com um produto final já conhecido, é muito importante. É este o objecto da Química Verde, que em muitos aspectos se confunde com a Engenharia Química.

6. Da mesma forma, a concepção e aperfeiçoamento de técnicas de análise que permitam determinar com rigor, rapidez e baixo custo as concentrações de milhares de constituintes de importância química e bioquímica, nas águas de consumo, nos alimentos, no sangue humano, e na atmosfera, por exemplo, é essencial para a manutenção e melhoria da qualidade de vida.

\section{Conclusão}

A Química é uma ciência que combina actividade teórica com actividade experimental (esta última nem sempre no laboratório!), e em que interpreta- mos o que vemos (escala macroscópica) baseados numa realidade microscópica subjacente (átomos e moléculas). É uma ciência profundamente enraizada no mundo em que vivemos, pois existe química em tudo o que nos rodeia e em nós próprios. É também uma ciência sensorial, que apela directamente aos sentidos, sobretudo à visão (as cores) e ao olfacto (os cheiros). Qual o químico que não aprecia os odores dos solventes de laboratório, nem sempre agradáveis mas familiares, e que não se maravilha com um ponto de viragem ou com uma chama colorida? A Química está ainda na base do paladar (gastronomia molecular!), e participa mesmo em todos os sentidos através da neuroquímica.

Ao entrarmos no novo ano, os fogos de artifício e as saudações com vinho espumante foram demonstrações simples, mas vibrantes e calorosas, de Química. Viva 2011!

\title{
0 Que Seria de Nós Sem a Química? 0 Programa da SPQ para o Ano Internacional da Química 2011 - Centenário da SPQ
}

\author{
JOAQUIM LUís FARIA*
}

A química é a ciência central: ela faz a ligação entre todas as outras ciências. É a ciência que muda o mundo, e fá-lo literalmente, pois é a ciência da matéria e das suas múltiplas transformações. Desde as profundezas da Terra à vastidão do espaço, da essência do ser até para lá da vida, a química responde às exigências da nossa existência, melhora os nossos padrões de vida, prolonga a nossa longevidade colectiva. Sem a química simplesmente não seríamos.

Da Terra extraímos os minérios e o crude para produzirmos as estruturas que constituem as nossas cidades e alimentam as nossas necessidades de energia. Da atmosfera recolhemos o nitrogénio que aplicamos na produção dos nossos alimentos. Do Sol chega-nos a energia, teoricamente em quantidade suficiente para suprir todas as nossas necessidades imediatas e vindouras. Assim houvesse

\footnotetext{
Secretário Geral da SPQ
}

(jlfaria@fe.up.pt) engenho para aproveitar essa fonte, pese embora mesmo aí a química não tenha dito a última palavra... Ionge disso.

A essência da vida, o nosso código genético, é química. A escrita, leitura e compreensão desse código constrói-se com 4 letras (A, G, T, C) desenhadas a partir de número reduzido de elementos químicos. Essas letras agrupam-se em combinações binárias determinadas por 2 ou 3 ligações químicas - ligações de hidrogénio. $A$ função básica que nos permite viver, o processo de respiração, envolve em si várias reacções químicas. Foi a química que nos deu os medicamentos, que nos permitem combater as doenças e melhorar as nossas expectativas de vida. Mesmo depois de perecermos fisicamente, os elementos na nossa constituição incorporam de novo os diferentes ciclos activos no ecossistema que nos acolhe.

O Ano Internacional da Química 2011 faz justiça à evolução e ao desenvol- vimento registado ao longo da nossa existência. É uma oportunidade para nos relembrar aonde chegamos, qual o impacto da química na nossa realidade de todos os dias e o que ainda podemos alcançar.

Por feliz coincidência, 2011 é também o centenário da sociedade científica que mais contribui para a divulgação da química em Portugal: a nossa Sociedade Portuguesa de Química, fundada em 28 de Dezembro de 1911 num movimento de um pequeno grupo de cientistas portugueses, liderado por Ferreira da Silva, director da Faculdade de Ciências da então recém-criada Universidade do Porto e primeiro presidente da Sociedade.

Convém aqui relembrar os objectivos da SPQ, tal como estabelecidos nos seus estatutos e que visam promover, cultivar e desenvolver, em Portugal, a investigação, o ensino e a aplicação da Química e das Ciências com esta mais directamente relacionadas. A estes juntamos em 2011 o nosso com- 
promisso para com os objectivos do AIQ numa perspectiva nacional, sempre em sintonia com as restantes sociedades e associações de Química e com os pressupostos estabelecidos pela UNESCO e pela IUPAC.

Queremos levar a química para fora das escolas, das universidades, dos laboratórios, das fábricas e dos meios especializados, para junto do Homem comum, criando uma percepção pública da importância da química, não só ao nível tecnológico, mas também social. O impacto da química na sociedade, nas artes e nas relações geopolíticas, deve ser reconhecido a par da sua importância na promoção do bem-estar da humanidade através do seu contributos na medicina, nas várias indústrias, na agricultura e na produção e armazenamento de energia. Sobretudo queremos neutralizar o negativismo da química normalmente associado aos impactos ambientais. $\mathrm{Na}$ maioria dos casos é maior o benefício que o prejuízo, e existe muita demagogia na utilização de impressões do nosso imaginário colectivo: a boa fruta é a fruta sem "químicos" (abreviatura grosseira de produtos químicos), mas no entanto toda ela é química na sua essência; a resistência à engenharia genética, quando a produção de alimentos geneticamente modificados permitiria reduzir a utilização de pesticidas químicos.

A química como ciência da transformação deve ser apreciada por todos. É a transformação dos materiais que nos permite criar automóveis mais leves que consomem menos energia. Os corantes que incorporamos nos materiais do nosso dia-a-dia e que dão cor à nossa existência, não seriam tão variados sem o auxílio da química. $E$ a cor não é apenas uma característica lúdica, tem enorme impacto ao nível da segurança, do ensino e da própria investigação científica. A química vai

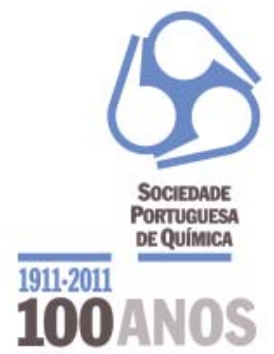

Logótipo do Centenário para além dos limites da ciência, faz parte da nossa vida diária.

\section{A Comissão Nacional AIQ 2011-SPQ 100}

A estratégia da SPQ na persecução destes objectivos é acima de tudo a de promover que as instituições dotadas de meios materiais e humanos adequados usem esses mesmos meios de forma concertada e ainda mais eficiente. A sociedade reconhece a sua limitação como patrocinador, já que é ela própria beneficiária e por isso assumirá sobretudo o seu papel como agente mobilizador de todos os químicos, professores e estudantes de química que entendam útil associarem-se às comemorações. Assim, convidámos a integrar uma Comissão Nacional criada para o efeito, presidida pelo Professor Jorge Carreira Gonçalves Calado, tendo como vice-presidente o Professor José Artur Martinho Simões, todos os representantes dos departamentos de Química, Bioquímica e Engenharia Química, bem como de outros departamentos ou instituições onde a química tenha um papel relevante (por exemplo, faculdades de Farmácia e departamentos de Materiais), capazes de estabelecer um diálogo produtivo que se traduzisse efectivamente numa acção concertada.

A Comissão reuniu em Coimbra a 2 de Dezembro de 2010, fez um levantamento exaustivo de todas as actividades planeadas por cada departamento/instituição e tentou encontrar formas de coordenar e complementar as actividades propostas. O espírito que caracterizou essa reunião foi fantástico e permitiu construir um programa variado e diversificado que pode ser apreciado na separata a este número do boletim. Esse programa é apenas indicativo pois estão constantemente a chegar-nos novas propostas, pelo que a informação aí contida deve ser considerada actualizada à data da sua emissão. Paralelamente, criámos um portal (www.spq.pt/quimica2011) onde pode encontrar esse programa de forma mais interactiva e funcional. O portal permite ainda colocar actividades que serão tornadas visíveis após validação no espaço de pouco horas. Pode mesmo juntar as suas contribuições nesse local.

\section{Ano Internacional da QUÍMICA 2011}

Versão nacional do logótipo do Ano Internacional da Química 2011

Na reunião de Coimbra, surgiram inúmeras ideias que se encontram a ser exploradas: actividades simples, como desafios nas escolas para a criação de calendários, concursos que promovam a interacção da química com a música, criação de autocolantes com frases sobre a química... Vamos chamar as empresas tradicionais, como a Viarco, Renova, Vinho do Porto e Confiança a produzirem materiais alusivos ao evento. Neste espírito, a SPQ lança neste mesmo número um desafio às escolas (ver "Os Químicos e o Ano Internacional da Química" por Mário Berberan e Santos).

A reunião de Coimbra só foi possível graças ao envolvimento da Ciência Viva. A SPQ está a trabalhar conjuntamente com esta instituição de modo a estabelecer um conjunto de parcerias que envolvam acções de formação, conjuntos de palestras, sessões laboratoriais e outras que se pretendem levar a cabo usando a rede de centros Ciência Viva.

Reafirmar a química como ciência central e motivar os jovens para a sua aprendizagem. É necessário melhorar o seu ensino contextualizado nas escolas e adaptar os currículos de formação básico e secundário. Reforçar o seu papel no ensino superior, devolvendo-Ihe o espaço merecido nos currículos científicos, especialmente nas áreas das engenharias. Vamos manter e reforçar o nosso empenho na realização das acções tradicionais, como as Olimpíadas de Química. Temos em curso as Olimpíadas de Química Júnior para a população do básico ( $8^{\circ}$ e $\left.9^{\circ} \mathrm{Ano}\right)$ e as Olimpíadas de Química + para o secundário $\left(10^{\circ}\right.$ e $11^{\circ}$ Ano). Cientes de que a procura pelas escolas tem vindo a aumentar estamos a estudar formas de incrementar a nossa resposta, alargando 


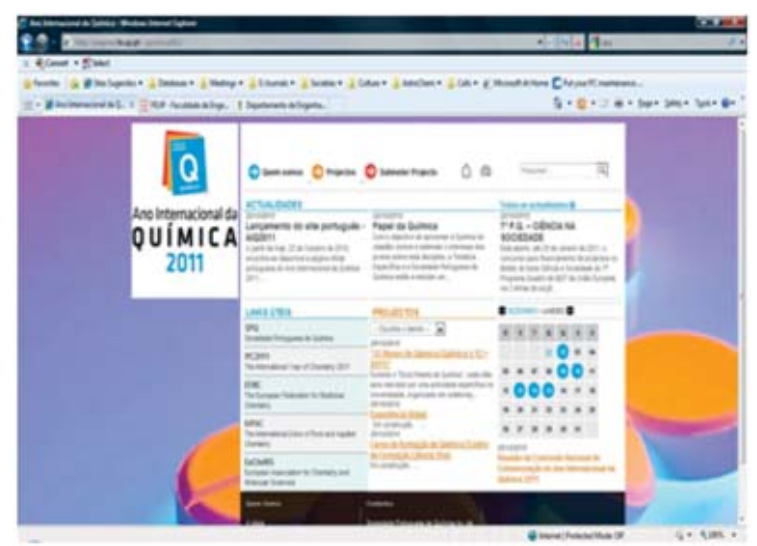

A página do AIQ 2011. Aqui pode introduzir o seu próprio projecto e ver o que se está a fazer dia-a-dia

o número de instituições envolvidas. Por outro lado, de modo a promover a internacionalização e aumentar a cooperação institucional manteremos enquanto possível a nossa participação nas Olimpíadas Internacionais de Química (International Chemistry Olympiad - IChO) e nas Olimpíadas Ibero-americanas de Química. Além disso poderemos promover colaborações bilaterais com regiões vizinhas, na sequência de propostas de cooperação específicas. Actualmente está em estudo a organização de uma prova finalíssima, ou de um projecto conjunto, envolvendo os vencedores da Olimpíada de Química Júnior, com os correspondentes espanhóis da prova organizada pela Associação Nacional de Químicos de Espanha (ANQUE).

Estamos ainda dispostos a ir às escolas com palestras, demonstrações e actividades, tendo reactivado e actualizado a carteira de palestras de SPQ. Estas palestras podem ser requisitadas pelas escolas para serem apresentadas localmente. A lista pode ser consultada em ambos os portais SPQ ou AIQ2011 (www.spq.pt).

Numa tentativa de aproximar a química do público e da sociedade civil contamos promover a publicação de livros e artigos, realizar conferências, palestras, debates, exposições, ciclos de cinema e outras actividades. A SPQ estará presente na edição, promoção ou divulgação de vários livros, entre eles a tradução da "História Química de uma Vela" de Michael Faraday, a edição conjunta com Porto Ciência de "Ferreira da Silva e o Laboratório Chimico Municipal do Porto" e a divulgação de "HAJA LUZ - Uma História da Química Através de Tudo" de Jorge Calado, pela IST Press.

Faremos a inserção nos órgãos de comunicação social de notícias, imagens, reportagens, entrevistas e debates sobre a química, os trabalhos e os feitos dos químicos, as suas grandes figuras e o seu impacto no nosso quotidiano.

Temos em preparação um magazine semanal, com duração prevista para 3'00, numa série de 13 programas. Cada emissão será centrada num tema diferente, onde vamos demonstrar de forma dinâmica e apelativa o papel da química, em diferentes áreas. A apresentação, que se pretende educativa, tentará ao mesmo tempo dar a conhecer investigadores e entidades nacionais de destaque na área da Química. Cada emissão fechará com uma rubrica de 15 segundos de "Sabia que..." sobre pequenas informações e curiosidades sobre a química.

Teremos também uma presença regular na imprensa escrita, estando pre-

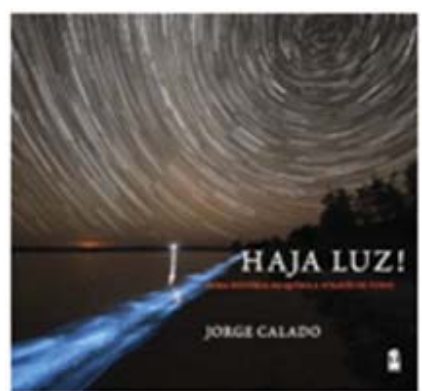

O livro que será lançado a 31 de Março de 2011 no Laboratório Chimico/Museu da Ciência Lisboa, "HAJA LUZ - Uma História da Química Através de Tudo" de Jorge Calado, pela IST Press vista a publicação de entrevistas em várias revistas.

Para aumentar a percepção pública da química está em produção a emissão de um conjunto de cartazes alusivos a temas chave da química. Estes cartazes, realizados segundo uma ideia da American Chemical Society, poderão ser descarregados do portal do AIQ 2011 e utilizados para uma ampla divulgação. Os cartazes serão mais tarde complementados por um conjunto de apresentações digitais que poderão ser requisitadas para exibições generalistas sobre a química.

Estamos a trabalhar na tradução de um filme promocional para o AIQ 2011, produzido conjuntamente pela European Petrochemical Association (EPCA), a UNESCO e a IUPAC, que visa mostrar a importância da química no nosso quotidiano. "CHEMISTRY: All About You" mostra como a química vai de encontro às necessidades do mundo desenvolvido, é criativa e produtiva, é inspiradora e celebra a contribuição permanente das mulheres para a ciência (2011 é também o centenário da atribuição do Prémio Nobel a Marie Curie). É um filme dinâmico e com uma mensagem direccionada aos jovens na faixa etária dos 16 aos 20 anos.

Pensamos em apoiar espectáculos, exposições e exibições onde a química apareça ligada às artes. Foi-nos apresentado o projecto Quorum Ballet-Química (www.quorumballet.com) que consiste num espectáculo de dança contemporânea tendo como tema base a química. $\mathrm{O}$ espectáculo de dança contemporânea é uma criação coreográfica original de Daniel Cardoso, director artístico e coreógrafo residente da companhia.

Water-A Chemical Solution: Uma Experiência Global para o Ano Internacional da Química é uma actividade que reúne estudantes de todo o mundo para participar de acções que destacam o papel da química nas questões da qualidade da água e saneamento. Alunos do ensino básico são convidados a explorar um dos recursos mais importantes da Terra, 


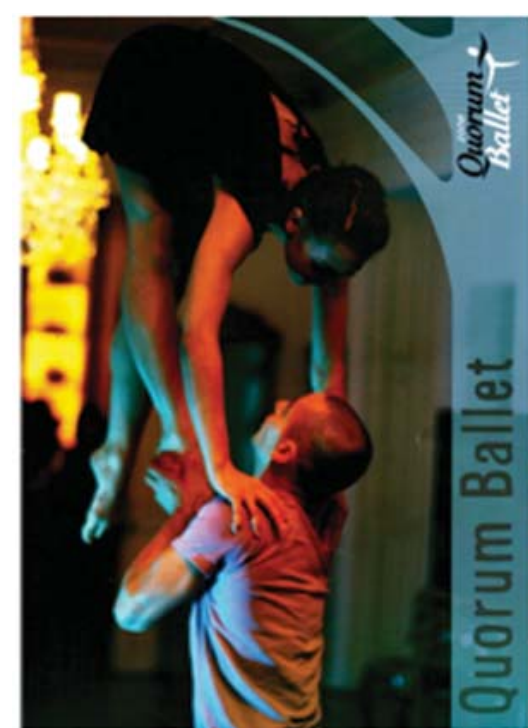

Dança contemporânea Quorum Ballet-Química. A ideia original e promoção da iniciativa são da autoria de Ana Paula Paiva, professora do Departamento de Química e Bioquímica da Faculdade de Ciências da Universidade de Lisboa (DQB-FCUL)

a água. Os alunos irão colocar os seus resultados sobre a qualidade e tratamento de água num mapa mundial usando a rede global, de forma a comparar resultados e contactar com outros colegas espalhados pelo globo. A experiência global é uma ini- ciativa da Comissão de Educação em Química da IUPAC. Inclui actualmente quatro actividades destinadas a cobrir conceitos químicos básicos mas capazes de despertar a curiosidade, com recurso a equipamentos simples. Pretende-se que os professores trabalhem com as suas turmas nas quatro actividades, dando aos estudantes uma visão geral de conceitos como acidez, salinidade, filtração e purificação de água. Esta experiência está a ser coordenada em Portugal pela Prof. Filomena Camões da FCUL, em colaboração com a SPQ.

Além destas actividades, a SPQ continuará com as suas acções e eventos regulares, de onde se destaca o XXII Encontro Nacional - 100 Anos de Química em Portugal. O evento decorrerá em Braga de 3 a 6 de JuIho, sob os auspícios da Delegação de Braga da SPQ, em colaboração com o Departamento de Química da Universidade do Minho, no Parque de Exposições de Braga. O encontro é organizado pelo Prof. João Paulo André (UMinho) e à semelhança dos encontros nacionais anteriores, inclui- rá a lição plenária do Prémio Ferreira da Silva, sendo igualmente atribuída a Medalha Vicente Seabra. Pela primeira vez será entregue o Prémio Romão Dias, no domínio da Química Inorgânica. Paralelamente, a Universidade do Minho tem também um programa específico para o AIQ 2011 onde se destaca uma exposição sobre Marie Curie, que estará patente durante o Encontro.

As celebrações do Ano Internacional da Química 2011 e do Centenário da SPQ são uma comemoração dos químicos portugueses. Os seus objectivos só podem ser atingidos com o envolvimento empenhado de todas as pessoas e instituições que se dedicam à investigação, ensino, aplicação e difusão da química em Portugal. A química faz parte da história colectiva do desenvolvimento da humanidade, daquilo que somos hoje e da forma como vivemos. O que seria de nós sem a química? Olhe à sua volta e tente identificar quais os objectos, seres ou materiais que poderiam existir sem que a química tivesse participado no processo da sua criação...

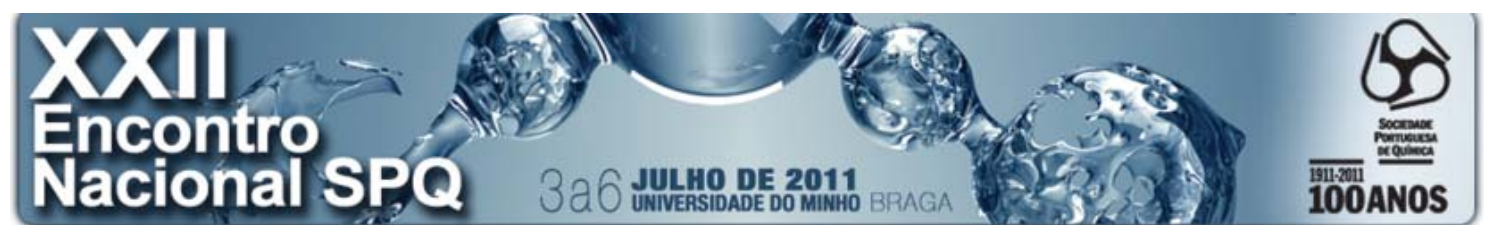

3 a 6 de Julho de 2011. "Cem Anos de Química em Portugal" será o tema do XXII Encontro Nacional, integrado não só nas comemorações do centenário da SPQ como também do Ano Internacional da Química

\section{Actividades Planeadas Pelo Departamento de Química da Universidade do Minho no Âmbito do Ano Internacional da Química}

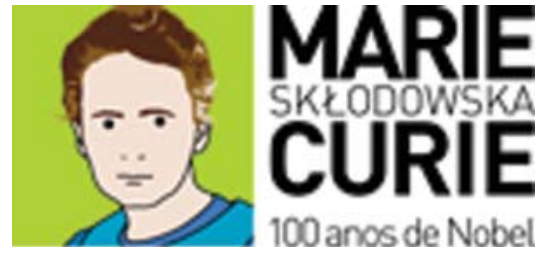

$\mathrm{O}$ ano em que se comemora o centenário da atribuição do Prémio Nobel da Química a Marie Curie, foi decretado pela UNESCO o Ano Internacional da Química (AIQ). Por uma feliz coincidência, 2011 é também o ano em que se comemora o centenário da SPQ.

Para assinalar estas efemérides, o Departamento de Química da UMinho projectou um conjunto de eventos e actividades em torno da personalida- de notável de Marie Curie, sob o título "A Beleza do Decaimento: Marie Curie e a História de um Nobel".

As comemorações do AIQ na UMinho tiveram início no dia 27 de Janeiro, numa cerimónia de lançamento que decorreu em simultâneo com a abertura oficial do AIQ na UNESCO, em Paris. A abertura foi oficializada através de uma conferência de imprensa, seguindo-se duas palestras apresentadas pelo Prof. Miguel Castanho e pela Prof. $^{a}$ Raquel Gonçalves-Maia. Esta ocasião contou ainda com a apresentação do livro mais recente da Prof. ${ }^{a}$ Raquel Gonçalves-Maia, dedicado a Dorothy Hodgkin, uma das quatro muIheres até hoje laureadas com o Pré-

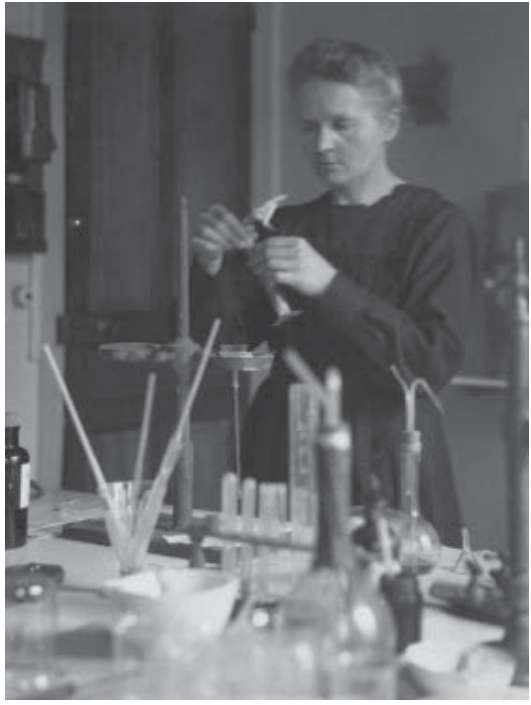

Madame Curie a trabalhar no seu laboratório (Imagem cedida pelo Museu Curie de Paris) 